\title{
Speciation Versus Phenotypic Plasticity in Coral Inhabiting Barnacles: Darwin's Observations in an Ecological Context
}

\author{
O. Mokady, ${ }^{1}$ Y. Loya, ${ }^{2}$ Y. Achituv, ${ }^{3}$ E. Geffen, ${ }^{1}$ D. Graur, ${ }^{2}$ S. Rozenblatt, ${ }^{4}$ I. Brickner $^{2,3}$ \\ ${ }^{1}$ Institute for Nature Conservation Research, The George S. Wise Faculty of Life Sciences, Tel Aviv University, Tel Aviv 69978, Israel \\ ${ }^{2}$ Department of Zoology, The George S. Wise Faculty of Life Sciences, Tel Aviv University, Tel Aviv 69978, Israel \\ ${ }^{3}$ Faculty of Life Sciences, Bar Ilan University, Ramat Gan 52900, Israel \\ ${ }^{4}$ Department of Molecular Microbiology and Biotechnology, The George S. Wise Faculty of Life Sciences, Tel Aviv University, \\ Tel Aviv 69978, Israel
}

Received: 18 January 1999 / Accepted: 9 May 1999

\begin{abstract}
Speciation and phenotypic plasticity are two extreme strategic modes enabling a given taxon to populate a broad ecological niche. One of the organismal models which stimulated Darwin's ideas on speciation was the Cirripedia (barnacles), to which he dedicated a large monograph. In several cases, including the coralinhabiting barnacle genera Savignium and Cantellius (formerly Pyrgoma and Creusia, respectively), Darwin assigned barnacle specimens to morphological "varieties" (as opposed to species) within a genus. Despite having been the subject of taxonomic investigations and revisions ever since, the significance of these varieties has never been examined with respect to host-associated speciation processes. Here we provide evidence from molecular (12S mt rDNA sequences) and micromorphological (SEM) studies, suggesting that these closely related barnacle genera utilize opposite strategies for populating a suite of live-coral substrates. Cantellius demonstrates a relatively low genetic variability, despite inhabiting a wide range of corals. The species $C$. pallidus alone was found on three coral families, belonging to distinct higher-order classification units. In contrast, Savignium barnacles exhibit large between- and within-species variations with respect to both micromorphology and DNA sequences, with $S$. dentatum "varieties" clustering phylogenetically according to their coral host species (all
\end{abstract}

Correspondence to: O. Mokady: e-mail: mokady@post.tau.ac.il of which are members of a single family). Thus, whereas Savignium seems to have undergone intense hostassociated speciation over a relatively narrow taxonomic range of hosts, Cantellius shows phenotypic plasticity over a much larger range. This dichotomy correlates with differences in life-history parameters between these barnacle taxa, including host-infestation characteristics, reproductive strategies, and larval trophic type.

Key words: Phylogenetic reconstruction - Speciation - Phenotypic plasticity - Pyrgomatine barnacles - Cantellius - Savignium - $12 \mathrm{~S}$ mt rDNA

\section{Introduction}

The high level of diversity among coral reef invertebrates and its potential for improving our understanding of the evolutionary mechanisms governing speciation processes have attracted considerable attention in recent years (e.g., Romano and Palumbi 1996). Advanced methodologies, including high-resolution morphological techniques [e.g., scanning electron microscopy (SEM) studies] and molecular tools, enable identification of complexes of sibling species (Knowlton et al. 1992; Van Veghel and Bak 1993; Knowlton 1993) for readdressing ecological and evolutionary questions (Knowlton and Jackson 1994). 
Table 1. Red Sea coral-inhabiting and free-living barnacles examined in this study and their typical substrates

\begin{tabular}{ll}
\hline Barnacle species & Substrate \\
\hline Savignium dentatum & Cyphastrea chalcidicum \\
& Favites abdita \\
& Favia favus \\
& Platygyra lamellina \\
Savignium elongatum & Echinopora gemmacea \\
Savignium crenatum & Acanthastrea echinata \\
Savignium milleporum & Platygyra lamellina \\
Cantellius pallidus & Millepora dichotoma \\
& Cyphastrea chalcidicum \\
Cantellius arcuatus & Montipora erythraea \\
Tetraclita squamosa & Pavona cactus \\
Balanus amphitrite & Porites lobata \\
& Pocillopora damicornis \\
& Intertidal rock (free living) \\
& Intertidal rock (free living) \\
\hline
\end{tabular}

Here we examine coral-inhabiting barnacles (subfamily Pyrgomatinae) belonging to two genera (Savignium and Cantellius). Obligate coral symbionts in this group are said to have become markedly specialized for living within a continuously growing substratum, such as living coral colonies, in both morphological and growth characteristics (Ross and Newman 1973; Young and Christoffersen 1984).

In barnacles, which reproduce by internal fertilization, adaptations for epizoic life that promote larval host specificity will form a reproductive barrier. Reproductive isolation, in turn, will lead to speciation (Templeton 1989). Alternatively, adaptations which do not promote host specificity will probably lead to some degree of phenotypic plasticity, in response to variations among the coral hosts. Savignium, reported to be specific to coral suborders (Ross and Newman 1973) and genera (Ogawa and Matsuzaki 1992), is considered to demonstrate a higher degree of host specificity than Cantellius. These two pyrgomatine barnacles were therefore chosen as model systems for contrasting speciation and phenotypic plasticity.

Coral-inhabiting barnacles were reported to exhibit substantial phenotypic plasticity by Darwin (1854) and numerous times since. Darwin's assignment of the three Savignium dentatum "varieties" is embedded in the cur- rent taxonomy of barnacles, which is considered a wellfounded one. A number of studies have subsequently assigned barnacles to these "varieties," with no attempt to interpret the observed differences ecologically (e.g., Hiro 1935; Foster 1980; Soong and Chang 1983).

Barnacle taxonomy, fundamentally established over a century ago by Darwin (1854), has only recently been reevaluated with the aid of molecular tools (e.g., Van Syoc 1995). In the current study we use molecular data (12S mt rDNA sequences), in conjunction with SEM observations, to test for indications of speciation within acknowledged species (sibling species). We use the data to reexamine some of the ecological conclusions that have traditionally been drawn upon the currently accepted taxonomy and correlate the findings with several known life-history characteristics of these barnacles.

\section{Materials and Methods}

\section{Animal Collection and SEM Observations}

Fragments of coral colonies inhabited by barnacles were observed in situ and collected at a depth of 1-30 m near the northern tip of the Gulf of Eilat, Red Sea, Israel. Twelve species of scleractinian corals and one hydrocoral (Millepora dichotoma), hosting six currently recognized species of barnacles (four Savignium and two Cantellius species) were sampled (see Table 1 for a complete list of hosts and symbionts). Barnacle shells were carefully removed from the coral and the soft parts and calcareous parts (i.e., shell plates and valves) were separated for identification and description (Brickner 1994). Shells and valves of coral-inhabiting barnacles were dehydrated in an alcohol series and coated with gold-palladium. Specimens thus prepared were examined by SEM (JEOL-840).

In addition, we collected two species of rock-inhabiting barnacles, Tetraclita squamosa and Balanus amphitrite, from nearby intertidal rocks, to serve as outgroups for the molecular analysis.

\section{DNA Preparation, Amplification, and Sequencing}

To extract total cellular DNA, the whole soft tissue of individual barnacles was homogenized in lysis buffer (10 mM Tris-HCl pH 8.0, 100 $\mathrm{m} M \mathrm{NaCl}, 20 \mathrm{~m} M$ EDTA, $0.5 \%$ lauryl sarcosine). The lysate was digested for $1 \mathrm{~h}$ by proteinase $\mathrm{K}(25-50 \mu \mathrm{g} / \mathrm{ml})$ at $55^{\circ} \mathrm{C}$ and extracted with phenol:chloroform (1:1). Nucleic acids were precipitated overnight with $0.1 \mathrm{vol}$ of $3 \mathrm{M}$ sodium acetate and $2 \mathrm{vol}$ of $100 \%$ ethanol, at $-20^{\circ} \mathrm{C}$. The pelleted nucleic acids were washed in $100 \%$ ethanol, dried, and resuspended in $100 \mu \mathrm{l} \mathrm{H}_{2} \mathrm{O}$.

The polymerase chain reaction (PCR) was employed to amplify a fragment of the $12 \mathrm{~S}$ subunit of the mitochondrial rDNA using the
Fig. 1. Partial sequence of the $12 \mathrm{~S}$ mt rDNA from coral-inhabiting barnacles and free-living barnacles (EMBL accession numbers $\mathrm{X} 78234-\mathrm{X} 78254)$. The substrate inhabited by each barnacle species is indicated in parentheses. Each sequence represents an individual barnacle, collected from a separate coral colony or intertidal rock, except for the sequences of $S$. milleporum and $S$. dentatum (Fav) I, each of which represents two identical sequences obtained from two individuals from separate colonies. A dot in a sequence indicates that the nucleotide in this position is the same as in the C. pallidus (Cyp) sequence. Stem coding regions are indicated above the sequences, and the numbers (32-48) correspond to the numbering used by Hickson et al. (1996). Complementary sequences assumed to form a stem are marked by the same number (e.g., 32 and 32'). Asterisks denote positions for which full complementarity is observed between stemforming sequences. The "A" at position 31 and the " $\mathrm{T}$ " at position 327 (underlined) correspond to positions 1160 and 1468 in the human sequence (Anderson et al. 1981), respectively. Aca, Acanthastrea echinata; Cyp, Cyphastrea chalcidicum; Ech, Echinopora gemmacea; Fav, Favia favus; Fat, Favites abdita; Mil, Millepora dichotoma; Mon, Montipora erythraea; Pav, Pavona varians; Pla, Platygyra lamellina; Poc, Pocillopora damicornis; Por, Porites lobata. 
C. pallidus (CYp)

C. pallidus (Mon)

C. palliaus (Pav)

C. arcuatus (Por)

S. crenatum (ACa) I

S. crenatum (ACa) II

$S$. crenatum (Pla)

S. dentatum (Cyp) I

S. dentatum (CYp) II

S. dentatum (Fat) I

S. dentatum (Fat) II

S. dentatum (Fav) I

S. dentatum (Fav) II

S. dentatum (Pla) I

S. dentatum (Pla) II

$S$. elongatum (ECh)

S. milleporum (Mil)

T. squamosa (rock)

$B$. amphitrite (rock)

C. pallidus (Cyp)

C. pallidus (Mon)

C. pallidus (Pav)

C. arcuatus (POC)

C. arcuatus (Por)

S. crenatum (Aca) I

S. crenatum (ACa)

$S$. crenatum ( $P l a)$

S. dentatum (Cyp) I

S. dentatum (CYp) II

S. dentatum (Fat) I

$S$. dentatum (Fat) II

S. dentatum (Fav) I

$S$. dentatum (Fav) I

s. dentatum (Pla) I

$S$. dentatum (Pla) II

$S$. elongatum (ECh)

S. milleporum (Mil)

T. squamosa (rock)

B. amphitrite (rock)

C. pallidus (Cyp)

C. pallidus (Mon)

C. pallidus ( $\mathrm{Pav}$ )

C. arcuatus (POC)

C. arcuatus (Por)

S. crenatum (Aca) I

S. crenatum (ACa) II

S. crenatum (P1a)

$S$. dentatum (Cyp) I

$S$. dentatum (Cyp) II

S. dentatum (Fat) I

s. dentatum (Fat) II

$S$. dentatum (Fav) I

S. dentatum (Fav) II

S. dentatum (PIa) I

$S$. dentatum (PIa) II

$S$. elongatum (Ech)

s. milleporum (Mil)

T. squamosa (rock)

B. amphitrite (rock)

C. pallidus (Cyp)

c. pallidus (Mon)

C. pallidus (Pav)

C. arcuatus (Poc)

C. arcuatus (Por)

S. crenatum (ACa) I

S. crenatum (ACa) II

$S$. crenatum (Pla)

S. dentatum (Cyp) I

$S$. dentatum (Cyp) II

S. dentatum (Fat) I

S. dentatum (Fat) I

S. dentatum (Fav) I

S. dentatum (Fav) II

S. dentatum (Pla) I

S. dentatum (Pla) II

S. elongatum (ECh)

S. milleporum (Mil)

T. squamosa (rock)

B. amphitrite (rock) $\leq \quad 32$

$\leq 33\rangle$

3

$\leq 35-$

AAAATATTTT-GGAATAGTAGTAATAAATGAATTTAACGGATTTGGCGCAAGATAGCCATITAGAGGAACCTGCCCTATAAAC

$\ldots \ldots \ldots \ldots \ldots \ldots \ldots \ldots \ldots \ldots$ T.

T.G. -

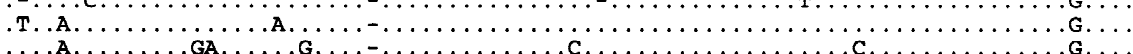

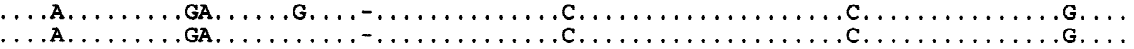
................... Аㅡㄹ .G. $\ldots \ldots \ldots \ldots$ A.T. $\ldots$ т. $\ldots$ т. $\ldots$ са. $\ldots$ т.

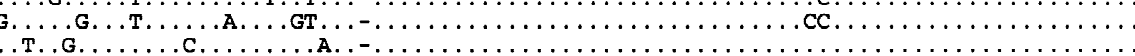

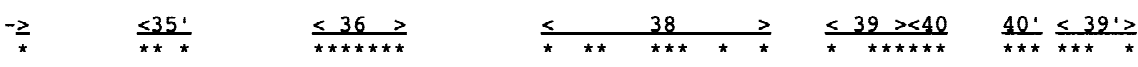
GATGATCCACGAT-GAACTTTACTTTTATTTGTATTTCAGTTTGTATACCGCTGTTGTCAGTCAGTTTCTTTAGAAACTTTCAC

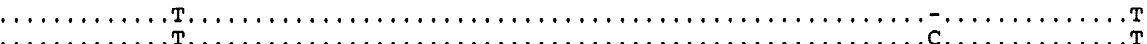

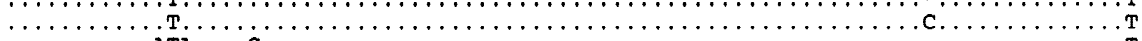

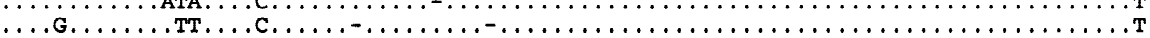

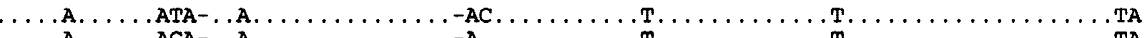
$\ldots \ldots$ А. . . АCA $\ldots$ А. $\ldots \ldots \ldots \ldots$-А $\ldots \ldots \ldots$ Т. $\ldots \ldots \ldots$ T. $\ldots \ldots \ldots$ TA

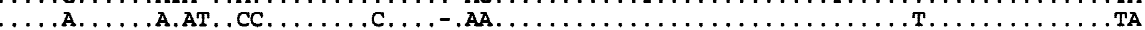

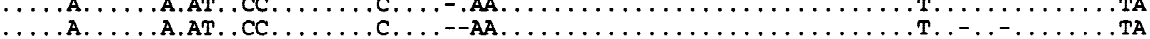

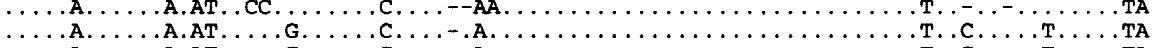

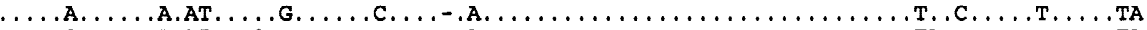

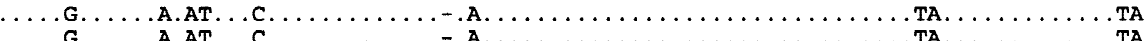

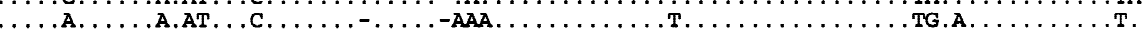

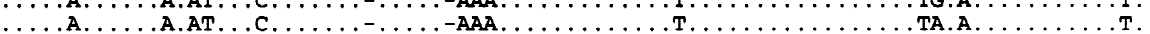

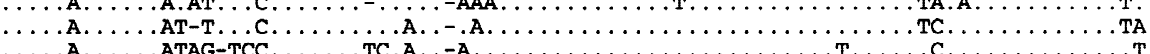

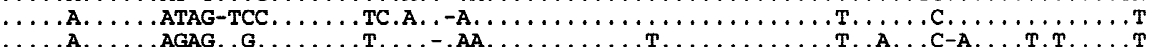

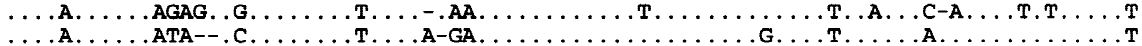

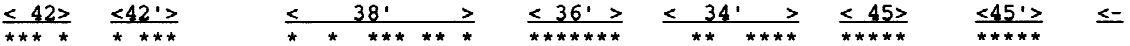
TCATGATAAAACCATTGACTTCAAGTAAAGGTGCAGCTTATATAAAAGACAGAGGTGGGTTACATTTAATA-GATTAAAACGGAT

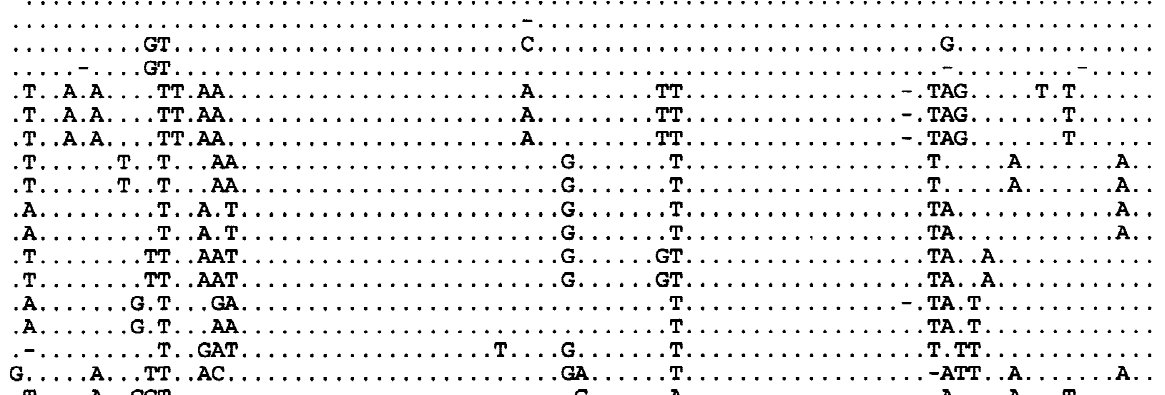

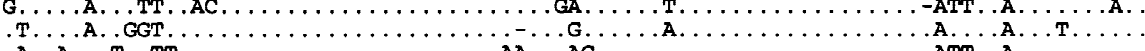

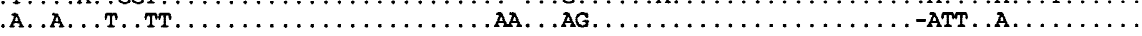

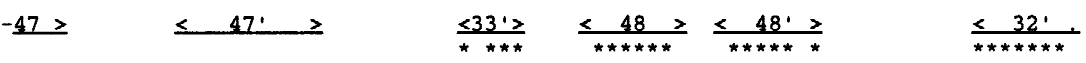

TAAG---TTGTGAATATAGCTTTTGAAGGTGGATT-AATTGTAAAGTTTATAAAA-CT-TGACGTGAGCTCTATCTTGT

$\ldots \ldots$
$\ldots \ldots$
А. T.


primer set of Kocher et al. (1989) as modified by Mokady et al. (1994): 5'-GAAACCAGGATTAGATACCC and 5'-TTTCCCGCGAGCGACGGGCG. The reaction buffer consisted of $10 \mathrm{~m} M$ Tris- $\mathrm{HCl}(\mathrm{pH}$ 9.0), $50 \mathrm{mM} \mathrm{KCl}, 0.1 \%$ Triton $\mathrm{X}-100$, and $3.5 \mathrm{mM} \mathrm{MgCl}$. Fifty-five picomoles of each primer was added for each reaction, along with 2.5 $\mathrm{U}$ of Taq DNA polymerase (Promega, Madison, WI), a $300 \mu M$ concentration of each dNTP, and $1 \mu l$ of template DNA solution in a total volume of $100 \mu \mathrm{l}$. The PCR cycle consisted of $2 \mathrm{~min}$ of denaturation at $92^{\circ} \mathrm{C}, 2 \mathrm{~min}$ of annealing at $54^{\circ} \mathrm{C}$, and $3 \mathrm{~min}$ of elongation at $72^{\circ} \mathrm{C}$. This cycle was repeated 29 times, with a final cycle in which the elongation time was $10 \mathrm{~min}$.

PCR products of the correct size (approximately $450 \mathrm{bp}$, which in most cases was the only visible band) were excised from a $0.8 \%$ agarose gel and purified using JETSORB and the manufacturer's protocol (GENOMED). The PCR product was resuspended in $25 \mu \mathrm{l} \mathrm{H}_{2} \mathrm{O}$. For bidirectional sequencing, $100 \mathrm{nmol}$ of DNA (typically 6-9 $\mu \mathrm{l}$ of the purified DNA solution) was separately mixed with $10 \mathrm{pmol}$ of each primer in a total volume of $10 \mu \mathrm{l}$. Sequences were determined with an automatic sequencer (Applied Biosystems 373A). Sequences analyzed in this study were deposited in the EMBL Database under accession numbers X78234-X78254.

\section{Sequence Alignment and Phylogenetic Analyses}

Sequences were aligned using CLUSTAL V (Higgins et al. 1992), with a fixed-gap penalty of 10 and a floating-gap penalty of 5. The data matrix thus produced consisted of 334 positions for all taxa (Fig. 1).

Phylogenetic reconstruction was carried out according to the optimality criteria of maximum likelihood (fastDNAml 1.0.6) and maximum parsimony [PAUP 3.1 (Swofford 1993)], in addition to a distance-matrix based neighbor-joining analysis [Phylip 3.5 (Felsenstein 1989)]. To test the validity of the clusters obtained by the above phylogenetic reconstructions, sequences of coral inhabiting barnacles were subjected to spectral analysis [Spectrum 2.0 (Charleston and Page 1997); see Hendy and Penny (1993) for details on the application of spectral analysis]. The aim of spectral analysis is to evaluate the relative support of each of the possible grouping combinations of taxa in a given data set. The method is independent of any phylogenetic assumptions, and thus provides a robust statistical test for the significance of clades observed in the phylogenetic trees generated under various assumptions (e.g., most parsimonious evolution).

Each of these methods uses a different set of assumptions, based on different evolutionary models. Thus, each of the methods involves expressed and implied limitations and capabilities for phylogenetic reconstruction (see, e.g., Hillis and Moritz 1990; Li and Graur 1991). We decided to utilize a suite of methods and to examine the data by different approaches, to increase the confidence in our results and conclusions. We used two rock-inhabiting barnacles, Tetraclita squamosa and Balanus amphitrite, as outgroups. A transition/transversion ratio of 1.13 was calculated from the data and used in the maximumlikelihood analysis, in which the option "global rearrangements" was invoked. DNA distances for the neighbor-joining analysis were calculated according to the "Kimura two-parameter" model. Both gaps and missing data were treated as missing data. Parsimony analysis was repeated, applying a recently suggested weighting factor for sequences coding for stem-and-loop rRNA structures [0.61 for stem regions, 1 for loop regions (Springer et al. 1995)]. Assignment of stem and loop regions was based on a model published by Hickson et al. (1996).

\section{Results}

\section{Morphology}

An exhaustive morphological description of the barnacles examined is beyond the scope of this study and was the subject of a separate report (Brickner 1994). Some of the observations, however, are of special relevance to the present study, and these are highlighted below.

Four morphological varieties of $S$. dentatum were identified during the course of the current study (for complete descriptions see Brickner 1994). Interestingly, each variety is specific to a different faviid coral host (Cyphastrea chalcidicum, Favia favus, Favites abdita, and Platygyra lamellina). Scanning electron micrographs of shells and terga of the different $S$. dentatum are shown in Fig. 2. Shell texture (digit-like projections) and the morphology of the tergum in $S$. dentatum from the coral Cyphastrea (Figs. 2A and B) are markedly different from those of other S. dentatum. It is very difficult to compare the varieties of $S$. dentatum found in this study with those described by Darwin (1854) from the coral Meandrina spongiosa, based on the drawings he presented. The variety reported here from Cyphastrea seems most similar to "variety 1" found by Foster (1980) on various corals in Hong Kong.

Table 2 compares $S$. dentatum from the four coral hosts, according to various morphological features. Only characters with two alternative states (i.e., unambiguously scoreable binary characters) are presented. These were extracted from a more comprehensive comparison, including the size ranges of various soft and calcareous body parts (Brickner 1994).

Several of the morphological characters used are scorable only in $S$. dentatum, and not in any of the other barnacles examined (characters are either ambiguous or irrelevant). Consequently, a very limited number of characters can be used to compare all the barnacles used in this study. Since it is impossible to resolve the phylogeny of so many taxa based on so few morphological characters, it was impossible to extrapolate the above morphological comparison to encompass barnacles other than $S$. dentatum.

The degree of calcification by the coral over the barnacle's shell plate varies widely. Calcification is slight or absent in S. dentatum (Fig. 2), S. elongatum, and S. crenatum. In contrast, the shells of $S$. milleporum are covered by a thick layer of hydrocoral skeletal material (Fig. 3B). The openings of individual polyps are clearly seen on that surface. Similar calcification over the barnacle's shell is also seen in Cantellius.

The SEM of the fused valves of S. elongatum (Fig. 3C) shows the articular ridge connecting the valves, which is similar to the tooth articulating the valves of $S$. dentatum. This feature may be of importance when considering possible phylogenetic relationships among the barnacles. Note that the tergal tooth in S. elongatum is perpendicular to the basal margin (Fig. 3C). This orientation resembles the situation in $S$. dentatum from $C y$ phastrea and Favites, but not in those from Favia or 

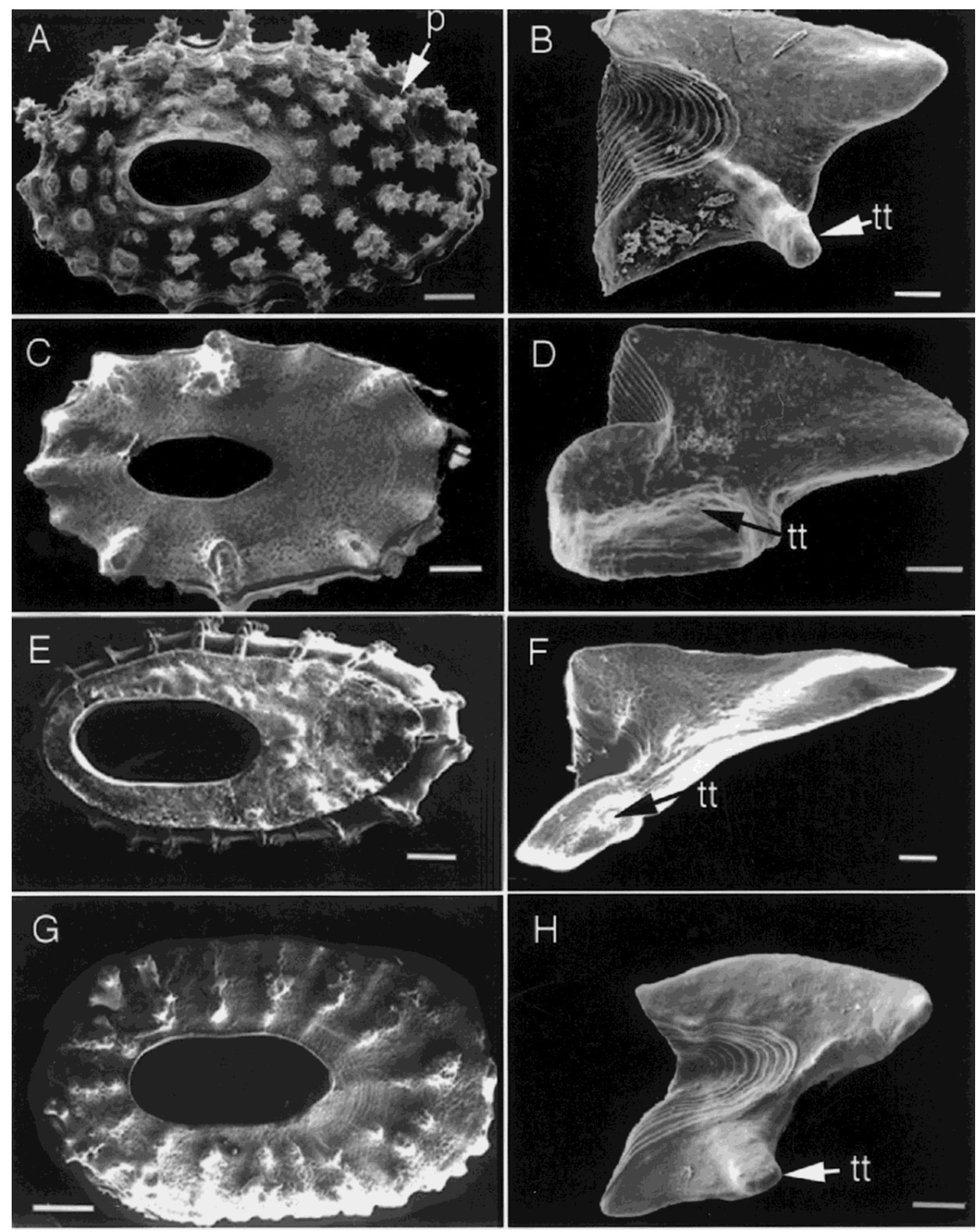

Fig. 2. SEM of Savignium dentatum shells (A, C, E, G) and terga (B, D, F, H). Barnacles were collected from C. chalcidicum (A, B), P. lamellina (C, D), F. favus (E, F); and F. abdita (G, H). p, shell projections; tt, tergal tooth. Scale bars: (A) $400 \mu \mathrm{m}$; (B, F) $100 \mu \mathrm{m}$; (C, E) $500 \mu \mathrm{m}$; (D) 200 $\mu \mathrm{m}$; (G) $1 \mathrm{~mm}$; (H) $300 \mu \mathrm{m}$.

Platygyra where the tergal tooth is oriented in parallel to the basal margin (Fig. 2; see Table 2).

\section{mtDNA Sequences}

A fragment of the $12 \mathrm{~S}$ mitochondrial rDNA (small subunit) was PCR amplified from individual barnacles. The aligned sequences (as shown in Fig. 1) were used for reconstructing phylogenetic trees based on maximumlikelihood and parsimony criteria and, also, by neighbor joining (Fig. 4). Tree topology was nearly identical whether the optimality criterion used was maximum likelihood or parsimony, and the results obtained are presented in a single tree (Fig. 4A). The following statistics characterize the four equally parsimonious trees obtained by the parsimony analysis: tree length $=249$, consistency index $=0.683$, and retention index $=0.755$. No topological changes were introduced by differential weighting of stem-and-loop stretches (see methods and Fig. 1), relative to the tree shown in Fig. 4A.

The tree produced by neighbor joining (Fig. 4B) is displayed as an alternative because of two notable differences in topology - the precise relative positions of Savignium dentatum barnacles from different hosts, which is probably of minor significance for the purposes of this study, and the position of the $S$. crenatum cluster.

A total of 131,072 "splits" was analyzed in the spectral analysis. The following ranks were obtained for 
Table 2. Comparison of Savignium dentatum extracted from different coral host species according to some morphological features

\begin{tabular}{|c|c|c|c|c|}
\hline & \multicolumn{4}{|c|}{ Coral host } \\
\hline & $\begin{array}{l}\text { Cyphastrea } \\
\text { chalcidicum }\end{array}$ & Favites abdita & Favia favus & $\begin{array}{l}\text { Platygyra } \\
\text { lamellina }\end{array}$ \\
\hline Position of tergal tooth relative to basal margin & Perpendicular & Perpendicular & Parallel & Parallel \\
\hline Presence of notch on maxilla I & - & + & + & + \\
\hline Pigmentation of cirri & - & + & + & + \\
\hline \multicolumn{5}{|l|}{ Denticles on } \\
\hline Endopodite I & - & + & + & + \\
\hline Endopodite III & - & + & + & + \\
\hline Exopodite III & - & - & + & + \\
\hline Apical seta on cirri IV-VI & Bifurcated & Bifurcated & Multifurcated & Multifurcated \\
\hline
\end{tabular}
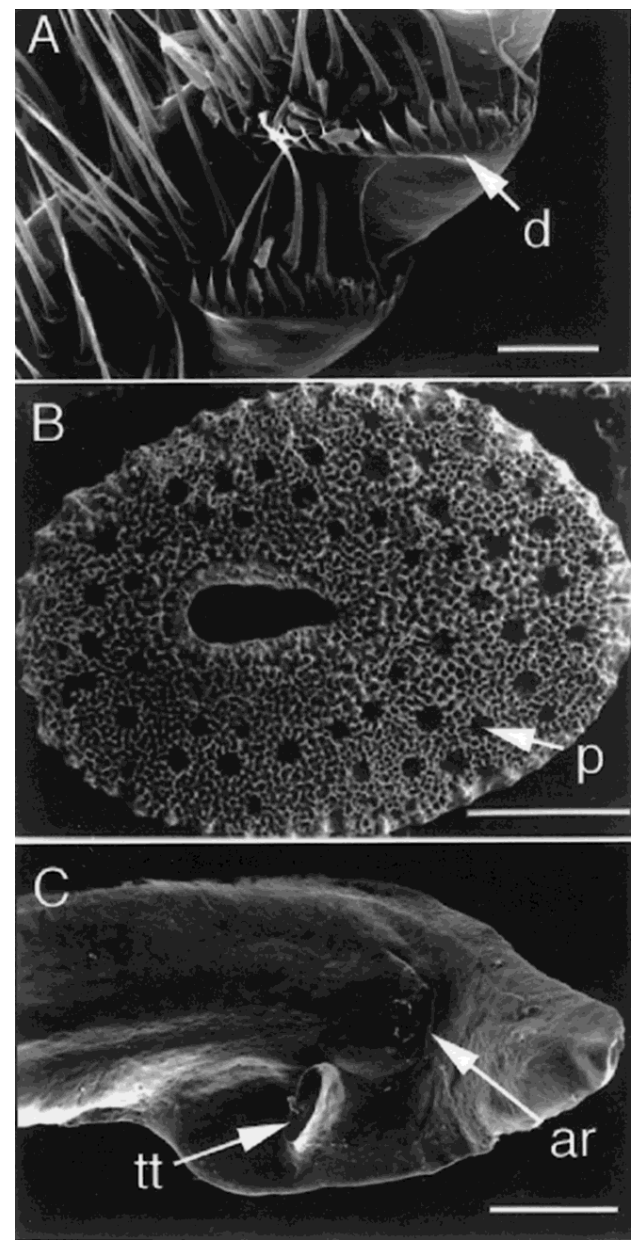

Fig. 3. SEM of various Savignium barnacles. A Segment from the endopodite of cirrus III from the barnacle $S$. dentatum inhabiting the coral F. abdita, showing denticles (d). Scale bar $=50 \mu \mathrm{m}$. B Top view of the shell of S. milleporum, showing polyp pores (p). Scale bar $=1$ $\mathrm{mm}$. C Opercular valve of $S$. elongatum. ar, articular ridge; tt, tergal tooth. Scale bar $=400 \mu \mathrm{m}$.

clades of interest within our reconstructed phylogeny (Fig. 4A): 1, S. crenatum (Acanthastrea I and II and Platygyra); 2, S. dentatum (Cyphastrea I and II); 3, S. dentatum (Platygyra I and II); 4, S. elongatum; 7, S. milleporum; 15, Cantellius sp.; 24, S. dentatum (Favites
I and II); 28, S. dentatum (Favia I and II). All these clades were assigned ranks that were at the top $0.02 \%$ of all possible combinations for that tree.

In both phylogenetic trees (Figs. 4A and B) all barnacles are clustered according to recognized species. Cantellius barnacles are also clustered together as a genus, whereas Savignium barnacles are not (note the position of S. milleporum). Sequence divergences observed between species and within species are radically different between Cantellius and Savignium barnacles. Different Cantellius species collected from different coral host species are tightly clustered; the average betweenspecies sequence divergence is $4.6 \%$ (range, $4.1-5.0 \%$ ). The average within-species sequence divergence between Cantellius barnacles collected from different coral hosts is $1.3 \%$ (range, $0.0-3.2 \%$ ). In contrast, the average between-species divergence in Savignium barnacles (excluding S. milleporum; see below) collected from different coral host species is $11.9 \%$ (range, 9.2-13.9\%), and the average within-species divergence is $7.9 \%$ (range, $3.5-11.1 \%)$.

The most striking point revealed by the reconstructed tree (Figs. 4A and B) is the magnitude of the distances between $S$. dentatum specimens collected from different coral hosts. While the average sequence divergence observed between specimens collected from the same host species is $0.7 \%$ (range, $0.3-1.5 \%$ ), the average divergence between $S$. dentatum from different host species is $8.3 \%$ (range, $5.5-11.1 \%$ ).

The basal position of $S$. milleporum is noteworthy (Figs. 4A and B), since it supports the notion that this barnacle should not be considered part of the genus Savignium, as indeed suggested by Anderson [(1992, 1993) genus nov. Wanella]. Additional implications of this basal position are discussed below.

\section{Discussion}

Three varieties of Savignium (formerly Pyrgoma) dentatum were recognized by Darwin (1854) over a century ago on the basis of morphological data. A number of 
A.

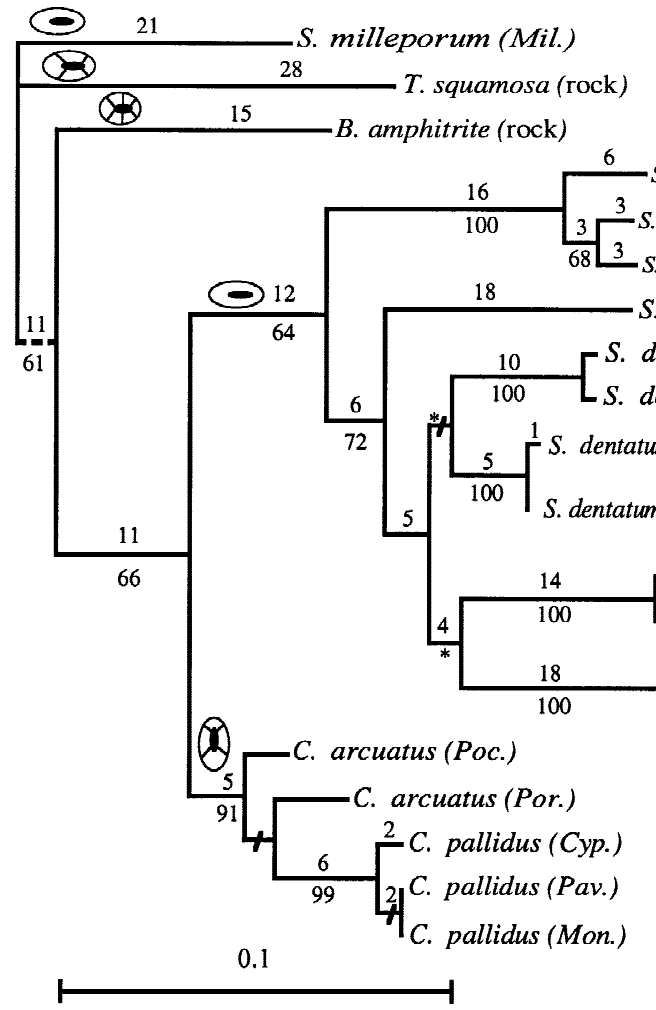

Fig. 4. Reconstruction of the phylogenetic relationships between coral-inhabiting and free-living barnacles extracted from different coral hosts and dead substrates (in parentheses; see Table 1 and Fig. 1 for a list of full taxonomic names for barnacles and corals). A A tree combining the results of reconstructions according to maximum likelihood and parsimony. The topology of the tree and branch lengths (note the scale bar) are those produced by maximum likelihood. Solid branches are significantly positive $(p<0.01$, except for the two branches marked by an asterisk, for which $p<0.05$; fastDNAml); The dashed branch is not significantly positive $(p>0.05)$. A " $50 \%$ majority rule" of four equally parsimonious trees supports the presented topology, with the
B.

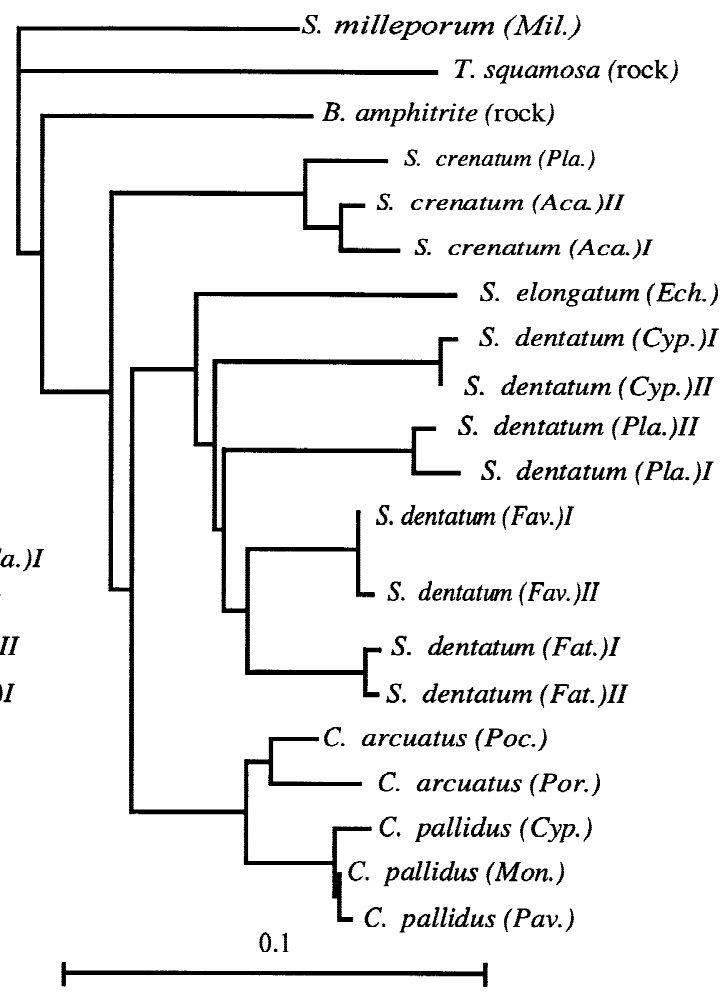

exception of the three branches crossed by a slanted line. Values to the left of a node relate to the maximum-parsimony analysis: the number of changes along the branch leading to the node is indicated above the branch (according to the parsimony-derived tree showing this precise topology); the percentage of 1000 bootstrap replications in which the group to the right of the node occurred is indicated below the branch (parsimony; only values $\geq 50$ are indicated). The number of shell plates (one in Savignium, four in Cantellius and Tetraclita, six in Balanus) is indicated graphically. B A neighbor joining-based phylogenetic reconstruction. Branch lengths reflect the percentage sequence divergence (note the scale bar). studies have subsequently assigned barnacles to these varieties, with no attempt to interpret the observed differences ecologically. Our findings, based on morphological and molecular data, indicate that $S$. dentatum "varieties" from the Red Sea cluster according to host species. This is an extension of previous reports, declaring the genus Savignium as being more specialized in terms of host specificity than Cantellius (Ross and Newman 1973; Ogawa and Matsuzaki 1992). It is also interesting to compare the way in which Savignium and Cantellius map onto the coral phylogeny recently produced based on 16S rDNA (Romano and Palumbi 1996), establishing a major division between "robust" and "complex" corals. While all coral species inhabited by Savignium belong to the robust type, Cantellius inhabits both robust and complex corals.

Host specificity at any of the above-mentioned levels suggests host-associated (possibly host-mediated or driven) speciation. Cases of host-associated speciation seem to be the rule in epizoic marine invertebrates
(Knowlton 1993), and the recognition of sibling species thus derived has a considerable influence on our views regarding many ecological and evolutionary questions (Knowlton and Jackson 1994). To the extent that host diversity plays a role in symbiont speciation, a higher diversity of hosts may promote a higher diversity of symbionts resulting from speciation. The current study reports four varieties of $S$. dentatum from the Red Sea. Foster (1980) has reported two varieties from Hong Kong, and Soong and Chang (1983) have reported only one variety from Taiwan. Coral species diversity was found to be high in the reefs of the Red Sea relative to other reefs sites (Sheppard et al. 1992), and a higher degree of host-associated speciation may be expected to occur on these reefs. However, both Hong Kong and Taiwan are much closer to the global maximum species diversity of corals (Veron 1995) than the Red Sea. The smaller number of $S$. dentatum varieties found in these localities may be due to local patterns of coral distribution or to factors other than host diversity. 
It is interesting to compare and contrast the degree of speciation in the two coral-inhabiting barnacle genera Savignium and Cantellius. According to the molecular data, within-species divergence is two to three times greater in S. dentatum than in S. crenatum or either of the Cantellius species examined (Fig. 4). In this context it is also noteworthy that between-species divergence is also much greater in Savignium than in Cantellius. Both barnacle genera inhabit a variety of coral hosts and show morphological differences according to the host on which they are found. However, whereas in Savignium the phenotypic differences are correlated with genetic differences (i.e., reflecting genetic isolation and possibly speciation processes), the phenotypic diversity demonstrated by Cantellius is not (i.e., phenotypic plasticity).

This suggested dichotomy (speciation vs. phenotypic plasticity) merits an exploration of possibly relevant lifehistory differences between Savignium and Cantellius. A critical point in the life cycle of coral-inhabiting barnacles is the stage of larval recruitment, during which host specificity is executed. In these sessile animals, where internal fertilization between adjacent individuals is the rule, larval motility is the only means for dispersion. Larvae of the two studied barnacle genera differ in a most important manner - the larvae of Savignium are lecithotrophic, while those of Cantellius are planktotrophic (Brickner, 1994). Lecithotrophic larvae typically have a shorter planktonic phase prior to recruitment (Scheltema, 1986). Cantellius larvae may therefore delay their settlement for longer periods of time. This feature may permit more efficient gene flow between remote populations, leading to lower rates of speciation and a higher degree of phenotypic plasticity due to differences in microhabitat (i.e., different coral hosts). On the other hand, an extended larval existence is also necessary for executing precise habitat selection (e.g., finding a particular host species), which leads to higher rates of hostassociated speciation. The case of Red Sea barnacles presented here is further complicated by the fact that both types of diversity (i.e., phenotypic plasticity and speciation) occur between populations/species inhabiting corals living in close proximity. Finally, when contrasting these two types of diversity, it is necessary to note that despite the large within-species differences revealed in this study (especially in $S$. dentatum), no species is suggested to be paraphyletic by our reconstructed phylogenetic trees.

The relative positions of different $S$. dentatum "varieties" in the reconstructed phylogenetic trees (Fig. 4) are not well supported by the morphological data (Table 2). According to the morphological characters listed in Table 2, S. dentatum barnacles can be divided into three groups, with individuals from Platygyra and Favia clustering closely in one group and those from Cyphastrea and Favites forming two separate additional groups.

On the other hand, the position of S. elongatum next to the "S. dentatum complex" in the molecular tree is supported by morphological data. The single, elongated opercular valve of S. elongatum is composed of two components in early ontogenetic stages, in which it resembles the morphology of $S$. dentatum opercular valves (see the "articular ridge" in the fused valve; Fig. 3C).

The position of S. milleporum at the root of the tree is consistent with the assignment of this barnacle to a new genus [Wanella (Anderson 1993)]. In fact, since both Tetraclita and Balanus are not pyrgomatides, S. milleporum may belong to a different higher taxonomic unit. This barnacle inhabits a hydrocoral (Millepora), in contrast with all the other epizoic barnacles examined in the current study, which inhabit scleractinian corals. The large genetic distance between S. milleporum and all the other epizoic barnacles further emphasizes the significance of the host in terms of speciation of the symbiont discussed earlier. However, additional assignments of new genera by Anderson (1992), by which members of the genus Savignium are divided into three genera based on functional morphology, are not supported by our findings. Specifically, our results do not support the grouping of S. elongatum and S. milleporum into one genus (Wanella), as well as the large distance implied between $S$. crenatum and other Savignium barnacles.

An evolutionary trend which is widely accepted for balanomorph barnacles is worth reconsidering in light of the basal position of $S$. milleporum in our reconstructed tree. According to that view, the number of shell plates has undergone gradual reduction along the evolution of balanomorphs (e.g., Anderson 1992). The classic taxonomic view places the intertidal free-living Balanus, having six shell plates, at the base of balanomorph phylogeny, with four- and one-plated pyrgomatides on higher branches. The trend of plate reduction has been traditionally attributed to the adaptation to living within a live substrate. This trend was a major factor in determining the phylogenetic relationships within the coralinhabiting pyrgomatides, i.e., that the four-plated Cantellius must have preceded the one-plated Savignium. Our data (Fig. 4A), together with a previous report of a four-plated stage in the ontogeny of Balanus (Glenner and Høeg 1993), suggest that plate reduction is not necessarily a unidirectional trend in balanomorphs.

Acknowledgments. The authors wish to thank the H. Steinitz Marine Biology Laboratory at the Interuniversity Institute, Eilat, for the use of diving facilities. Thanks are also due to an anonymous reviewer for a detailed review of the manuscript.

\section{References}

Anderson DT (1992) Structure, function and phylogeny of coralinhabiting barnacles (Cirripedia, Balanoidea). Zool J Linn Soc 106: 277-339

Anderson DT (1993) Addendum/corrigendum. Zool J Linn Soc 108: 377 
Anderson S, Bankier AT, Barrell BG, et al. (1981) Sequence and organization of the human mitochondrial genome. Nature 290:457465

Brickner I (1994) Ecology, systematics and phylogenetics of coral inhabiting barnacles in the Gulf of Eilat, PhD thesis. Bar Ilan University, Ramat Gan, Israel

Charleston MA, Page RDM (1997) Spectrum for Macintosh (PowerPC), version 2.0. Division of Environmental and Evolutionary Biology, Institute of Biomedical and Life Sciences, University of Glasgow, Glasgow, UK

Darwin C (1854) A monograph on the sub-class Cirripedia, with figures of all the species. The Balanidae (or sessile cirripeds); the Verrucidae, etc., etc., etc. London Ray Society, London

Felsenstein, J (1989) PHYLIP_Phylogeny inference package (version 3.2) Cladistics 5:164-166

Foster BA (1980) Shallow water barnacles from Hong Kong. In: Morton BS, Teng CK (eds) Proceedings of the First International Marine Biology Workshop. Hong Kong University Press, Hong Kong, pp 207-232

Glenner H, Høeg JT (1993) Scanning electron microscopy of metamorphosis in four species of barnacles (Cirripedia, Thoracica, Balanomorpha). Mar Biol 117:431-439

Hendy MD, Penny D (1993) Spectral analysis of phylogenetic data. J Classification 10:5-24

Hickson ER, Simon C, Cooper A, Spicer GS, Sullivan J, Penny D (1996) Conserved sequence motifs, alignment and secondary structure for the third domain of animal 12S rRNA. Mol Biol Evol 13:150-169

Higgins DG, Bleasby AJ, Fuchs R (1992) CLUSTALV: Improved software for multiple sequence alignment. CABIOS 8:189-191

Hillis DM, Moritz C (1990) Molecular systematics. Sinauer Associates, Sunderland, MA

Hiro, F (1935) A study of cirripeds associated with corals occurring in Tanabe Bay. Records Oceanogr Works Japan 7:1-28

Knowlton N (1993) Sibling species in the sea. Annu Rev Ecol Syst 24:189-216

Knowlton N, Jackson JBC (1994) New taxonomy and niche partitioning on coral reefs: Jack of all trades or master of some? TREE 9:7-9

Knowlton N, Weil E, Weight LA, Guzman HM (1992) Sibling species in Montastrea annularis, coral bleaching and the coral climate record. Science 255:330-333

Kocher TD, Thomas WK, Meyer A, et al. (1989) Dynamics of mitochondrial evolution in animals: Amplification and sequencing with conserved primers. Proc Natl Acad Sci USA. 86:6196-6200
Li W-H, Graur D (1991) Fundamentals of molecular evolution. Sinauer Associates, Sunderland, MA

Mokady O, Rozenblatt S, Graur D, Loya Y (1994) Coral-host specificity of Red Sea Lithophaga bivalves: Interspecific and intraspecific variation in $12 \mathrm{~S}$ mitochondrial ribosomal RNA. Mol Mar Biol Biotechnol 3:158-164

Ogawa K, Matsuzaki K (1992) An essay on host specificity, systematic taxonomy and evolution of the coral-barnacles. Bull Biogeogr Soc Japan 47:87-101

Romano SL, Palumbi SR (1996) Evolution of scleractinian corals inferred from molecular systematics. Science 271:640-642

Ross A, Newman WA (1973) Revision of the coral inhabiting barnacles (Cirripedia: Balanidae). Trans San Diego Soc Nat Hist 17:137-174

Scheltema RS (1986) Long-distance dispersal by planktonic larvae of shoal-water benthic invertebrates among central Pacific islands. Bull Mar Sci 39:241-256

Sheppard C, Price A, Roberts C (1992) Marine ecology of the Arabian region. Academic Press, London

Soong KY, Chang KH (1983) The coral-inhabiting barnacles (Crustacea: Thoracica: Pyrgomatidae) from southern most coast of Taiwan. Bull Inst Zool Acad Sinica 22:243-254

Springer MS, Hollar LJ, Burk A (1995) Compensatory substitution and the evolution of the mitochondrial $12 \mathrm{~S}$ rRNA gene in mammals. Mol Biol Evol 12:1138-1150

Swofford DL (1993) PAUP: Phylogenetic analysis using parsimony, version 3.1. Laboratory of Molecular Systematics, Smithsonian Institution, Washington DC

Templeton AR (1989) The meaning of species and speciation: A genetic perspective. In: Otte D, Endler JA (eds) Speciation and its consequences. Sinauer Associates, Sunderland, MA, pp 3-27

Van Syoc RJ (1995) Barnacle mitochondrial DNA: Determining genetic relationships among species of Pollicipes. In: Schram FR, Høeg JT (eds) New frontiers in barnacle evolution. A.A. Balkema, Rotterdam, pp 269-296

Van Veghel MLJ, Bak RPM (1993) Intraspecific variation of a dominant Caribbean reef building coral, Montastrea annularis: Genetic, behavioural and morphometric aspects. Mar Ecol Prog Ser 92:255265

Veron JEN (1995) Corals in space and time. UNSW Press, Sidney

Young PS, Christoffersen ML (1984) Recent coral barnacles of the genus Ceratoconcha (Cirripedia: Pyrgomatidae) from Northeast Brazil. Bull Mar Sci 35:239-252 